Fanum

Sociológico
Forum Sociológico

Série II

17 | 2007

Envelhecimento activo. Um novo paradigma

\title{
Da Ecologia Geral à Ecologia Humana
}

\section{Francisco Carvalho}

\section{(2) OpenEdition}

\section{Journals}

Edição electrónica

URL: https://journals.openedition.org/sociologico/1680

DOI: 10.4000/sociologico.1680

ISSN: 2182-7427

\section{Editora}

CICS.NOVA - Centro Interdisciplinar de Ciências Sociais da Universidade Nova de Lisboa

Edição impressa

Data de publição: 1 janeiro 2007

Paginação: 127-135

ISSN: 0872-8380

\section{Refêrencia eletrónica}

Francisco Carvalho, «Da Ecologia Geral à Ecologia Humana », Forum Sociológico [Online], 17 | 2007,

posto online no dia 01 janeiro 2007, consultado o 29 março 2022. URL: http://

journals.openedition.org/sociologico/1680 ; DOI: https://doi.org/10.4000/sociologico.1680 


\title{
DA ECOLOGIA GERAL À ECOLOGI A HUMANA
}

\author{
Francisco Carvalho \\ Doutor em Relações Internacionais (Ecologia Humana), Cesnova (francisco.carvalho@fcsh.unl.pt)
}

\begin{abstract}
Resumo
Apesar da ancestralidade e perenidade das relações Hom em -Ambiente o seu tratamento científico tardou, sendo preciso chegar-se ao início do século passado para que tal começasse a alterar-se. Desde então, tolerada, nuns casos, senão mesmo quase ignorada ou rejeitada, noutros casos, condicionada não raro pelo biologismo e o antropocentrismo extremados, umas vezes identificada com a Geografia e outras com a Sociologia, designadamente, outras ainda como capítulo ou extensão da Ecologia Geral, a Ecologia Humana foi interessando cientistas das várias disciplinas, suscitando convergências e, por aí, objecto de reorientação. Assim, após a década 70 do século $\mathrm{XX}$, retomada a ideia de ponte que já tinha ocorrido no início desse século, encarado em definitivo o Homem na sua globalidade biocultural, clarificado o objecto de estudo no contexto do diálogo Homem-Homem, Homem-Ambiente e introduzidos aperfeiçoamentos de metodologia, chega-se aos dias de hoje em que a Ecologia Humana é entendida como uma nova disciplina, um novo nível de pensamento, que procura interpretar os comportamentos da biosfera e da sociosfera. Neste artigo equaciona-se o porquê da Ecologia Humana, a lenta maturação que conheceu até ao seu entendimento na actualidade.
\end{abstract}

Palavras-chave: Ecologia, Ecologia Humana, evolução, ecossistema humano

\begin{abstract}
The relation between the Human race and the Environment is ancestral and permanent, yet its scientific study is quite recent. Only at the beginning of the last century some evolvements occur on the field. Since then the Human Ecology has originated different attitudes: simply tolerated by some, ignored and rejected by others, sometimes conditioned by radical biologic and anthropocentric views, sometimes perceived as Geography or Sociology, or viewed as a branch of the global Ecology. However, all these perceptions called the attention of the scientific community, which originated some convergence and re-orientation efforts. As a result, and after the $70^{\text {s }}$ decade of the last century, some fundamental evolvements occurred. The idea of the bridge that was present at the beginning of the century was recovered. A global biocultural approach was adopted to look at the human race. The study object of the relations Human being / Human being and Human being / Environment was clarified. Methodological improvements were introduced. Presently the Human Ecology is seen as a new scientific field, a new level of thought that fights to understand the behaviours of the biosphere and sociosphere. This paper questions the foundation of Human Ecology and the slow evolution it had until today.
\end{abstract}

Keywords: Ecology, Human Ecology, Evolution, Human Ecossystem.

\section{Porque não a Ecologia da espécie humana?}

A Ecologia enquanto ciência remonta aos finais do século XIX, destacando-se de entre os precursores mais próximos tanto Humboldt, cujo "Ensaio sobre a geografia das plantas", considerado o primeiro sistema de classificação das formas biológicas, contribuiu para a posterior ampliação do espaço de observação científica à escala planetária, como Darwin, a quem se deve principalmente a introdução de uma concepção dinâmica e evolutiva do tempo.

O termo Ecologia começou por ser utilizado por Haeckel em 1866, na sua "Morfologia geral do indivíduo" explicando então que a oekologie tinha por objecto descrever a teia de relações complexas que ligam os seres vivos ao ambiente que os rodeia, compreendendo em sentido lato o que Darwin chamara todas as "condições de existência". 
Haeckel propôs outras definições, mormente em 1868, quando ao ligar a tradição da Biogeografia à Economia da Natureza, concebe a "oekologie ou distribuição geográfica dos indivíduos " como "a ciência do conjunto das relações dos indivíduos com o mundo ambiente exterior, com as condições orgânicas e inorgânicas da existência; o que se chamou a economia da natureza, as relações mútuas de todos os indivíduos vivos num único e mesmo lugar, a sua adaptação ao meio que os envolve, a sua transformação pela luta para viver [...]" (Acot, 1988: 44). Pode dizer-se que em Haeckel a Ecologia constitui-se até certo ponto no quadro científico e ideológico da Economia da Natureza, dos equilíbrios naturais e da adaptação dos seres vivos às suas condições de existência (Acot, 1988).

Desde então a Ecologia conheceu significativas alterações. Começando por ser mais descritiva que analítica e espacialmente localizada, primeiro na Europa, depois no Novo Mundo, é hoje em dia cada vez mais universal. Por outro lado, tendo sido mais estática que dinâmica e mais centrada no estudo das plantas que no estudo dos animais, é nos nossos dias entendida como o ramo do saber que estuda as condições de existência dos seres vivos e as interacções, de toda e qualquer natureza, entre todos os seres vivos e os seus ambientes, estudo esse com base na abordagem sistémica.

A moderna Ecologia é também encarada numa perspectiva evolutiva, com a qual se procura explicar como os seres vivos se modificaram e diversificaram ao longo do tempo e os mecanismos que levaram a essa modificação, passando a incluir-se o Homem no processo evolutivo e, portanto, a considerá-lo parte integrante da biosfera (Avelar e Pité, 1996).

Ainda assim, a Ecologia Humana só a partir da década de 70 do século XX foi adquirindo autonomia científica. E porque seria assim? Ou seja, existindo a Ecologia dos peixes ou a Ecologia das aves, porque não a Ecologia da espécie humana? Afinal, nesta também intervêm factores bióticos, com as suas relações intraespecíficas e interespecíficas, e factores abióticos, que interferem na Ecologia das plantas e dos animais.

O que sucede é que o ser humano pertence a uma espécie muito peculiar, biologicam ente pouco dotada, vulnerável às doenças, que possui capacidade de comunicar com grande eficácia, de alterar o ambiente natural e de construir ambientes. Ora, os ambientes construídos são complexos e diversificados, integram elementos tão diferentes como a família, a habitação, os transportes, o trabalho, a organização social, a actividadade política, a religião, as emoções, os valores. Como diria Lessa (1984), o Homem é o único grupo zoológico dotado de espiritualidade.

Acresce que enquanto na Ecologia geral todas as espécies têm o mesmo interesse (sinecologia), na nossa disciplina a espécie humana converte-se em grupo de referência (auto-ecologia ou ecologia antropocêntrica). Ou seja, por um lado, o Homem, como qualquer outro indivíduo, é parte integrante da ecosfera e assim é encarado, o que não distingue a Ecologia Humana da Ecologia geral. Porém, e simultaneamente, a sua flexibilidade em termos de conduta, a capacidade para controlar as respectivas vizinhanças imediatas e para desenvolver cultura independentemente do ambiente, são maiores do que as dos outros organismos (Odum, 2001). E assim é tido como objecto de estudo, o que diferencia a nossa disciplina da Ecologia geral.

Sem esquecer que a espécie humana é heterotrófica, há, ainda, que atentar na sua grande mobilidade, característica que leva Nazareth (1996: 146) a referir que não se trata de "espécie normalmente localizada num determinado espaço, mas de uma espécie que se encontra em todas as altitudes e em todas latitudes, destruindo, por vezes, os ecossistemas naturais".

Conjugadamente com a mobilidade é também de realçar a flexibilidade das motivações e papéis, por vezes conflituantes, dos seres humanos na vida de relação, o que remete para a pertinente, quanto actual, interrogação de Acot (1988, contra-capa) "mudarão as relações dos homens com a natureza sem que mudem as relações dos homens consigo próprios?" Estamos de facto perante uma "espécie muito especial", que mais tarde ou mais cedo teria de ser abraçada pela Ecologia científica (Nazareth, 1996a). Como é que tal sucedeu?

\section{Os primórdios}

A despeito da universalidade e da perenidade das relações Hom em - Ambiente, só na última centúria é que essas interacções foram equacionadas no plano científico, culminando um percurso com avanços e recuos, controvérsias e equívocos, tanto no campo das ciências naturais como entre os cientistas sociais (Borden, 1991; UNESCO, 1986; Young, 1983).

Para melhor se entender tal evolução, há que recuar ao início do século XX e constatar como, então, as ciências naturais abriram o caminho à Ecologia Humana. Nessa altura, com efeito, temas como simbiose, competição, luta pela sobrevivência, dominação, evolução e comunidade como uma unidade, até aí de interesse exclusivo de ecólogos da natureza, passaram a interessar também os cientistas sociais.

A essa ponte que assim se estabelecia procurando encontrar semelhanças entre os problemas estudados pelos biólogos e os cientistas sociais, seguiu-se nos anos 20 uma outra concepção de Ecologia Humana que no entanto aparecia identificada com a Geografia Humana (Barrows, 1923). É a fase do estudo da diversidade dos comportamentos no 
espaço e das diferentes respostas sociais e culturais ao meio que na época mais fascinam os estudiosos da Ecologia Humana.

Ainda nos anos 20 é feita a distinção entre factores biossociais e psicossociais e reconhecida a sua interdependência recíproca, no âmbito da tentativa de classificar os ambientes, com a qual se inicia uma aproximação à visão moderna da Ecologia Humana (Machado, 1984; Nazareth, 2004). É também na década de 20 que aparece pela primeira vez um estudo referenciado à Ecologia Humana sobre os esquimós polares do Noroeste da Gronelândia publicado em $1921^{1}$ na revista Ecology, da autoria de Ekblaw e no qual esse geólogo e botânico analisa sob uma perspectiva global as relações entre uma antropocenose e os ambientes biótico e abiótico (Acot, 1988).

Se bem que inovadora, a abordagem de Ekblaw passou quase despercebida na época, o que de resto aconteceu com outras tentativas para incluir o estudo da espécie humana no âmbito da Ecologia científica. Foi o caso de um seu contemporâneo, o entomologista Forbes, a quem se deve a publicação, também na Ecology, em 1922, de um artigo com o titulo "A humanização da ecologia" (e subtítulo "Todas as formas de vida em relação com o ambiente"), onde o autor chega a sugerir que "poderia ser útil para nós ecólogos tentar ver o que é que as relações humanísticas da ecologia são actualmente" (Young, 1988:17).

Embora no artigo de Forbes subsistisse alguma ambiguidade, já que relevava em última instância de uma Ecologia Aplicada, houve, porém, uma preocupação em sublinhar que as relações Homem-Ambiente eram indissociáveis da Ecologia, ao considerar que o ser humano "é também um indivíduo e os indivíduos constituem uma parte do seu ambiente" (Acot, 1988: 168-169). Forbes considerava que o sistema ecológico mundial devia compreender a espécie humana enquanto espécie dominante, o que para a época constituia um avanço e um apelo a uma abordagem holística, embora embrionária, a despeito de o contexto científico de referência ainda não ser propício.

$\mathrm{Na}$ realidade, a investigação nos domínios da Ecologia, sobretudo da Ecologia Vegetal, encontrava-se em expansão, excluindo provisoriamente o Homem como objecto de estudo, enquanto ao nível da metodologia e prática do ensino da Biologia tardava a transmissão de saberes que proporcionassem uma real aproximação entre cientistas da natureza e cientistas sociais, como haveria de reconhecer nos meados da década de 30 o académico de Chicago Adams, grande adepto da Ecologia Dinâmica e impulsionador da Ecologia Animal. Para o entendimento da sua posição, expressa num artigo de 1935 sobre a relação entre a Ecologia Geral e a Ecologia Humana, vale a pena atentar-se na seguinte passagem (Young, 1983: 88):

\begin{abstract}
"Enquanto a biologia for principalmente ensinada e desenvolvida com base em fundamentos individualistas ou apenas agregativos, com um reconhecimento ligeiro ou insuficiente da dimensão comunitária, os estudantes das ciências vizinhas continuarão a utilizar e só aceitar os conceitos mais antigos e em consequência irão atrasar a integração das ciências biológicas e das ciências sociais".
\end{abstract}

Tal advertência/apelo de Adams surge quando a Sociologia americana desenvolvia vasta actividade, sobretudo através da "escola" de Chicago, também referenciada por "grupo" de Chicago, como Acot prefere dizer (1988: 170 e segs.), para a destrinçar da escola de Ecologia biológica forjada na Universidade de Chicago. De facto, a partir dos finais da década de 20 um grupo de sociólogos de Chicago, com destaque para Park, Burguess, McKenzie e discípulos, publicam trabalhos importantes de Sociologia Urbana (Brandão, 2003; Coulon, 1997). No entanto, o papel do ambiente físico foi subestimado, sendo a atenção centrada nos factores sociais e culturais, uma vez que para eles o campo próprio da Ecologia era o biótico e o da Ecologia Humana ou Social o nível cultural. A partir daí a Ecologia Humana chega a ser circunscrita à condição de componente da Sociologia, havendo autores que a consideravam "umbilicalmente ligada à sociologia" ou mesmo como "uma das sociologias" (Gonçalves, 1969: 91-92).

Ainda sobre a maturação da Ecologia Humana destaca-se a designada "escola de ecologia cultural", surgida nos Estados Unidos e onde pontifica Stweard, cujos trabalhos publicados na segunda metade da década de 30 levaram nos nossos dias Crognier (1994: 14) a apontá-lo como "promotor de uma etnologia em que ambiente e cultura estão em causalidade recíproca”. Já antes, Manners (Young, 1983), creditara-o como um pioneiro de uma "ecologia cultural", que ajudou a "mudar a face da antropologia", tanto do ponto de vista teórico e metodológico como em termos de introdução desse neologismo no meio académico.

Para o zoólogo e antropólogo Steward, o ambiente tinha um papel activo nos factos culturais, mas respeitava antes de tudo ao que Crognier chama "núcleo cultural", constituído pela Economia e a tecnologia. Uma sua monografia sobre um grupo de aborígenes do semiárido Oeste Americano, editada em 1938, veio a ser reconhecida como um clássico, embora a clareza do conceito de cultura ecológica não fosse ao tempo completamente conseguida, o que levou Steward a clarificar o seu ponto de vista sobre a cultura ecológica ao distanciar esta do determinismo geográfico, numa tentativa para equilibrar o ambiente com considerações sobre cultura, procurando assim encontrar um interface entre ambiente cultural e ambiente natural. 
Comentando o contributo de Steward, dado o interesse e a influência que cedo suscitou entre os antropólogos, Vayda e Rappaport escrevem em 1968 sobre "ecologia, cultura e não cultura" questionando-se acerca das razões da diversidade de comportamentos humanos face à domesticação de animais e à agricultura, bem como da criação e adopção de rituais de matança de animais (porcos) na Nova Guiné (Young, 1983). Nesse sentido, Vayda e Rappaport, embora apreciem em Steward as tentativas de rigor analítico, discordam das conclusões, dado o grau de inevitabilidade de correlação encontrada entre certos traços culturais e certas adaptações causais pondo mesmo em causa a existência de correlações significativas, vão advogar o que chamam de "ecologia unificada", no sentido da utilização de unidades da Ecologia Biológica para campo de estudo.

O aspecto mais actual da "ecologia cultural" de Steward, será o da atenção a dar à análise das relações de um grupo cultural com o seu ambiente de relação. É assim que Crognier (1994: 14, 16) considera haver em Antropologia uma convergência de pontos de vista com os avanços da Biologia das populações, que simultaneamente "vai preconizar o estudo aprofundado do ser humano considerado não ao nível da espécie, nem do indivíduo, mas na sua associação gregária e funcional que é a população", entendida como "o elemento humano de uma biocenese e por consequência de um ecossistema".

\section{Tempos de indefinição}

Na sequência do grupo de Chicago como da "escola de ecologia cultural", como ainda e por extensão durante a II Guerra ou mesmo no período que imediatamente se lhe sucedeu, são em geral inconsequentes as tentativas para integrar nas Ciências Sociais conceitos e métodos de uma Ecologia Geral em expansão no panorama científico da época.

Particularmente os anos 40-60 correspondem a um período incaracterístico, que variou entre um antropocentrismo extremo e uma visão redutora da Ecologia, inspirada em concepções deterministas sobre a influência do ambiente sobre o Homem, o que suscitou reacções diversas, incluindo indiferença e condescendência, no campo das Ciências Naturais e no das Ciências Sociais. Por um lado, o crescente interesse dos cientistas sociais pelo estudo das relações Homem-Ambiente provocou reservas entre os biólogos ecologistas, tanto mais que esse entusiasmo levou a que fosse excluído o papel dos ambientes abiótico e biótico, perdendo-se assim a perspectiva holística que hoje caracteriza a Ecologia Humana. Mas, por outro lado, também entre os cientistas sociais surgiram reacções, já que apesar do interesse da investigação científica pelas relações Homem-Ambiente ter permitido retirar a Ecologia do domínio quase exclusivo da Biologia e da Geografia, continuava a cair-se não raro no extremo oposto.

Foi o que sucedeu ao preconizar-se uma Ecologia Humana que funcionasse como síntese de todas as ciências sociais, como advogou Bews nos anos 30, embora the seja reconhecida uma preocupação em observar o ambiente-função-indivíduo como um todo integrado ${ }^{2}$, bem como o seu alerta quanto aos eventuais efeitos da amplitude desse ramo do saber poderem vir a torná-lo também difuso, ou mesmo incoerente. Foi, ainda, o que haveria de acontecer ao advogar-se que o objecto da ecologia fosse centrado no estudo de áreas marginais adjacentes de várias disciplinas, na sequência de uma proposta apresentada no termo da II Guerra por Wirth, também ele oriundo do grupo de Chicago, como forma de contrariar a tentativa de expansionismo que parecia subjacente em Bews (Young, 1988).

Tudo isso, porém, redundaria numa perspectiva de abordagem impraticável, pois o que se propunha atingia a integridade de cada uma das disciplinas e redundava em prolixidade, saindo assim prejudicada a visão de globalidade e de afirmação do próprio campo de acção da Ecologia Humana.

Reflexo do exposto foi a procura de reavaliação da abordagem ecológica pelas Ciências Sociais, em particular pela Sociologia, como resultado de críticas contundentes iniciadas com Alihan, autora de Conspectus of the ecological approach (Young, 1988:103 e segs), publicado em 1938. No essencial a autora questionava a legitimidade das Ciências Sociais, em especial da Sociologia, utilizarem conceitos e métodos da Ecologia Vegetal e Animal tal como era praticado pelo grupo de Chicago.

Em reacção a essas críticas, Catton e Dunlap (1983) haveriam de referir mais tarde que os sociólogos que enveredaram pela abordagem da Ecologia Humana com eçaram por perder força e desse modo mutilaram toda uma geração de cientistas sociais interessados no tema da Ecologia, para depois se lançarem num antropocentrismo extremado, ao ponto de ser defendido que os comportamentos humanos não necessitavam de qualquer referência ao ambiente, que a Sociologia tradicional podia explicar tudo sem recorrer a outras disciplinas ${ }^{3}$. Convirá dizer que Alihan não rejeitou a Ecologia Humana; apontando, isso sim, para uma reconceptualização. O seu clamor foi sobretudo contra os ecólogos da época, pelo grande apego manifestado relativamente à Sociologia tradicional, bem como pela inconsistência e falência em compreenderem o verdadeiro e real significado dos seus próprios postulados, incluindo a distinção comum entre comunidade como nível biótico e sociedade como nível cultural da organização humana. Para Alihan os sociólogos da Ecologia aderiram na época demasiado ao determinismo 
ambiental e paradoxalmente negaram-no outras tantas vezes o que, no seu entender, era revelador da pouca convicção que os animava. Alihan parece igualmente ter em vista a posição de certos ecólogos biologistas ao reprovar também a falta de consideração pelos factores volitivos da espécie humana, sublinhando a diferença entre os seres humanos e os demais seres vivos, não apenas no controle que têm do ambiente como na vontade de o fazer.

O que perpassa no que vem sendo tratado são as consequências dos determinismos de sinal contrário e mais ou menos acentuados, que assim se iriam manter ainda durante anos, condicionando a afirmação da Ecologia Humana. Mesmo as tentativas então feitas, com realce para Hawley, Quinn e Duncan, todos eles sociólogos de Chicago, que se estenderam até à década de 80 , para "(re)habilitar" a Ecologia Humana, continuavam a subvalorizar a importância dos ambientes abiótico e biótico nas antropocenoses (Carvalho, 2007; Nazareth, 2004).

A Ecologia Humana iria continuar a ser ainda identificada com a Sociologia, numa altura em que esta permanecia impregnada de uma certa tradição marcada pelo antropocentrismo e pelo cepticismo face ao biologismo.

\section{Transição para a moderna Ecologia}

Entretanto, depois da explosão, em 1945, da primeira bomba atómica e das consequências desse desastre ecológico, Ehrlich (1971) lança um alerta sobre os efeitos acumulados da explosão demográfica na biosfera, reflectido no livro intitulado significativamente por Bomba " $P$ " ( $P$ de população) e, logo depois, em 1972, vem o Clube de Roma pugnar pela imposição de limites ao crescimento, cujos fundamentos no entanto suscitam críticas e reservas (Sauvy, 1974; Tamames, 1983; Jacob, 1999).

De qualquer forma, conjugava-se um conjunto de circunstâncias conducentes ao crescendo do interesse pelo estudo das relações Homem-Ambiente, nem sempre isento do que Young chama de algum "provincianismo" e "chauvinismo", patenteado não raro por sociólogos, antropólogos e geógrafos, sobretudo, de par com biólogos, temperado pelos contributos de outros cultores desses ramos do saber que procuram sublinhar a importância da interdisciplinaridade.

Já quase no termo dos anos 60 perfila-se a tentativa de afirmação de uma Sociologia Ambiental, protagonizada por Catton e Dunlap (Young, 1983). É assim que para ultrapassar os postulados antropocêntricos informadores das relações Hom em Ambiente, o que aqueles autores chamam "paradigma da excepcionalidade humana", contrapõem um "novo paradigma ecológico", tomando por axioma a dependência das sociedades humanas relativamente aos ecossistemas naturais.
A despeito do "novo paradigma ecológico" ensaiado por Catton e Dunlap, o mesmo mereceu críticas centradas na própria operacionalização do que se propunha, face ao elevado grau de abstracção do axioma de que parte o referido paradigma, levando Buttel (1986) a propor uma teoria particular da Sociologia Ambiental para superar as generalizações daqueles autores (Cardeira, 1996).

Posteriormente, ainda no tocante ao tratamento pela Sociologia das questões ambientais, Beck e Giddens preconizam uma articulação entre as dimensões sociais e naturais perante os problemas de risco ecológico com que se confrontam as sociedades contemporâneas, no quadro da "sociologia de risco" (Ascher, 2000). Mas, a retoma desse interface entre as Ciências da Natureza e as Ciências Sociais, é algo que já se insere na fase actual de afirmação da moderna Ecologia Humana.

A década de 70 marca na realidade um ponto de viragem em direcção à moderna Ecologia Humana. Com ela são lançados os fundamentos de uma nova fase caracterizadora da disciplina na actualidade, os quais numa primeira aproximação nos parecem bem reflectidos na posição de Odum, um misto de imperativo alerta contra a dualidade reinante (antropocentrismo versus biologismo) e de contagiante apelo para a convergência de actuações, expressa nos termos seguintes:

\footnotetext{
"Chegou o momento de o homem administrar tanto a sua própria população como os recursos de que depende, dado que pela primeira vez na sua breve história se encontra perante limitações definitivas, e não puramente locais. O ordenam ento do ecossistema e a ecologia humana aplicada tornaram-se assim novos empreendimentos que requerem a fusão de um conjunto de disciplinas e de missões que até agora têm sido promovidas independentemente umas das outras" (Odum, 2001: 812).
}

Vale a pena dizer ainda que Odum, na sequência da posição recém-transcrita, constante da $3 .^{a}$ edição (1971) dos seus Fundamentos de Ecologia, não só reforça a exigência do papel de ponte entre as Ciências Naturais e Sociais num artigo na revista Science, em 1975, como, segundo Acot (1988:133-134), assinala a emergência da Ecologia como uma nova disciplina científica de matriz integradora, incluindo a espécie humana nesse processo. Clymer (Young, 1983: 4) sobressai no contexto do ressurgimento conceptual emergente, ao considerar que uma "nova síntese da informação existente é necessária em ordem a integrar conceitos de ecologia humana". 


\section{A Ecologia Humana na actualidade}

Na década de 70 a Ecologia Humana emerge como uma ponte entre as Ciências da Natureza e as Ciências Sociais, levando Odum (2001: 812) a reconhecer: "Agora [...], quase todas as disciplinas e profissões, tanto no campo das ciências como no das humanidades, estão ávidas por encontrar na área da ecologia humana um campo comum de encontro".

Também Lessa (1984: 10-11) se referiu à posição seguida nos anos 70 no contexto da afirmação da Ecologia Humana:

"Uma Assembleia Geral das Nações Unidas (1972) vinha de insistir que a Terra era uma só, [...] e que a coexistência harmónica do Homem com a Natureza era a questão fundamental deste fim do século [...] Mas sentira-se surpreendida por não haver em nenhum país uma escola superior que preparasse quadros adequados [...] Faltava uma pedagogia. Paris, Geneve e Toulouse encarregaram -se então de elaborar sobre um tronco com um de conhecimentos, um programa piloto pluridisciplinar. Criou-se um Centro Europeu de Ecologia Humana. Outras Universidades [...] vieram juntar-se. A Organização Mundial de Saúde chamou a si a condução final de um certificado internacional de Estudos e cinco anos depois [...] fez reunir uma dúzia de peritos para instalar um Grupo Coordenador de Ecologia Humana. Só que ao procurar enquadrá-lo [...] houve primeiro que a reclassificar, a redefinir [...] Concordaríam os que o fim da Ecologia Humana era "o estudo do homem na sua Circunstância ", - entendendo nós por "Circunstância" a adição da Natureza com a Sociedade; e que o seu estudo requeria um domínio muito grande de Biologia, de Antropologia, de Sociologia e de História das Civilizações diferentes [...] e com essas chaves se abririam depois horizontes tão vastos $[. . .]^{\prime \prime}$.

Como entender então a Ecologia Humana na actualidade?

$\mathrm{Na}$ actualidade é retomada a perspectiva global ensaiada no início do século $X X$ e introduzem-se aperfeiçoamentos de ordem metodológica (Nazareth, 1993, 1996; 2004). O Homem é definitivamente encarado na sua totalidade compósita, ou seja, enquanto sistema de órgãos e funções, dotado de instintos e de inteligência, possuidor de um património genético e cultural, inserido num meio formado por elementos bióticos, abióticos e sociais. Quer dizer, a totalidade humana é simultaneam ente totalidade biológica e totalidade cultural, - totalidade complexa, no dizer de Morin (1999). Por outro lado, temos o sistema - ambiente constituído pelo universo biótico, abiótico e social relativamente ao Homem.

Há, assim, dois sistemas em permanente interacção. O sistema-homem recebe como inform ações as alterações ocorridas no sistema-ambiente. Por sua vez, a descodificação das informações recebidas processa-se consoante o património (genético, imunoquímico, intelectual, cultural e afectivo) de cada um de nós. A elaboração da acção/resposta também depende de factores que variam em cada sistema-homem. Assim, a resposta do sistema-homem ao sistema-ambiente pode traduzir-se em alterações no próprio sistema-homem, tais como reacções vasculares (termorregulação), imunitárias e comportamentais, ou no sistema-ambiente, mormente traduzidas em intervenções no meio envolvente, como a construção de abrigos contra intempéries, climatização, diversas formas de agricultura, urbanização, alterações do regime político...

Nestas condições, a Ecologia Humana deixa de ser encarada como extensão, prolongamento ou capítulo da Ecologia Geral ou de outra ciência; como síntese de todas as ciências, estudo de áreas marginais das várias disciplinas ou somatório de determinadas áreas de diferentes ciências ou como um movimento de opinião. Tal como explica Nazareth (2004: 65), na actualidade é definida:

\footnotetext{
" [...] como o estudo das relações, em tempo e espaço, entre a espécie humana e as outras componentes e processos do ecossistema de que é parte integrante. O seu objectivo é conhecer a forma como as populações humanas concebem, usam e afectam o ambiente, bem como o tipo de respostas existentes às mudanças ocorridas no ambiente biológico, social e cultural".
}

Trata-se de uma ciência de base humana, aberta à transversalidade e à complexidade das problemáticas que estuda, interdisciplinar, na confluência entre as Ciências da Natureza e as Ciências Sociais, ligando o particularm ente natural e o particularm ente social, que rejeita predições deterministas. Ela introduz uma nova dimensão na conceptualização da Ecologia, qual é a hum anização dos comportamentos do Homem, enquanto resultantes da dinâmica das interacções entre si, com os ambientes com que se relaciona e destes relativamente ao ser humano (Lamy, 2001; Jaquard, 2004).

\section{Singularidade da Ecologia Humana}

A Ecologia Humana tem pois objecto de estudo, metodologia e objectivos prospectivos.

O objecto de estudo é, como se disse, constituído pelas interacções permanentes e recíprocas Homem-Ambientes (natural e construído). 
Ainda que a metodologia e as técnicas de observação e análise em Ecologia humana sejam igualmente as empregues por outras disciplinas, a sua singularidade e vocação interdisciplinar/transdisciplinar, emprestam-lhe a particularidade da ênfase na abordagem holística, que partilha com a Ecologia Geral, relativamente às problemáticas objecto de estudo sob novos e diferentes paradigmas. Ora, a abordagem holística supõe a utilização da metodologia sistémica, que na expressão de Rosnay (1995: 12 ) é simbolizada no "macroscópio" ( $m a c r o=$ grande e skopein=observar), esse instrumento imaginário que, cita-se, "filtra os pormenores, amplia o que os liga, põe em evidência o que os aproxima", qual olhar conceptual que nos possibilita perceber, reconhecer e descrever as formas globais. Isso porque, como resulta do exposto, a Ecologia Humana lida com o "infinitamente" complexo, no que tal significa de variedade, complementaridade, concorrência, incerteza, antinomia.

Por seu turno, a sua "primeira missão" - a expressão é de Crognier (1994: 5) - é "melhor conhecer os seres humanos para melhor os servir". Dizendo de outra forma, o seu objectivo fundamental é conciliar os comportamentos da sociosfera com os da biosfera. Assim, tendo em conta a dinâmica das interacções, a Ecologia Humana "estuda cada vez mais numa perspectiva global os diferentes 'climas' que actuam no homem - físico, químico, biológico, sociológico, económico, técnico, cultural, espiritual..." (Nazareth, 1996: 149).

À luz deste enquadramento temos, pois, que durante demasiado tem po o Homem esteve arredado do objecto de estudo da Ecologia, a despeito dos efeitos acumulados recíprocos das suas intervenções nos ambientes que o rodeiam - físico, social, cultural. Praticamente só a partir dos anos 70 é que os pontos de vista dos cientistas naturais e sociais começaram a fundir-se num consenso quanto ao papel da Ecologia Humana no diálogo Homem-Homem e Homem-Natureza. A propósito, Di Castri (Chabaud, 1984: 173), após interrogar-se sobre se a "ecologia é uma ciência da natureza ou uma ciência do homem", logo responde: "De uma e outra, mas não de uma natureza que exclua o homem, nem de uma humanidade desligada da natureza. Ciência, seguramente, mas que só poderá afirmar-se na medida em que aqueles que a praticam se sintam profundamente responsáveis quanto ao futuro da humanidade".

Assim, depois de ter sido recusada como ciência, a Ecologia Humana é agora considerada por alguns como um pleonasmo, já que, como refere Lamy (1995: 292), "a ecologia não poderia ser senão humana", até porque "o homem é parte integrante do sistema biosférico total, simultaneamente seu habitante e manipulador". Outros, como Crognier (1994), interrogam-se sobre se haverá uma ou várias "ecologias humanas", em razão da multidimensio- nalidade do seu campo de interesse, correntes de pensamento, diversidade das abordagens, sublinhando que sendo uma disciplina que "convoca os seus conceitos directores das ciências da natureza, é aliás uma Ecologia que atribui uma importância determinante aos contextos culturais e sociais e que em razão disso cobre um domínio híbrido".

Já Cam pbell (1988), discorrendo sobre o plano prático das perspectivas com que o estudo dos seres humanos é encarado em Ecologia Humana, aponta para o efeito duas correntes: cultural e social. A corrente cultural estuda como a cultura de um grupo humano se adapta aos recursos naturais do ambiente e à existência de outros grupos humanos. A corrente social, por seu turno, investiga os motivos que conduzem à estrutura social de um grupo humano a ser o resultado do ambiente global do grupo.

Num outro plano, Olivier (1981: 12-13) afirma que a Ecologia pode ser considerada sob os ângulos do curto e do longo prazos. Assim, o ângulo do curto prazo "refere-se às nossas condições de vida, saúde, equilíbrio, e resultados perniciosos da poluição (stress)", estando "estreitamente associada à demografia, à sociologia, à higiene e à medicina preventiva, assim como à defesa da natureza" Sobre a Ecologia de longo prazo e reportando ao ângulo seguido no trabalho citado, esclarece aquele autor que não se trata apenas das "repercussões imediatas do meio sobre nós próprios, mas da influência mais longínqua sobre os nossos descendentes".

Quer se trate da Ecologia Cultural ou da Ecologia Social, quer se fale da Ecologia de curto ou de longo prazos, a Ecologia Humana preocupa-se cada vez mais com a observação e a análise da teia de relações extremamente complexas - a "imperceptível rede de relações hiper-complexas", na expressão de Lefèvre-Witier - que ligam o Homem ao Homem e o Homem ao Ambiente plural (físico, químico ou biológico, social e cultural), apoiando-se no método sistémico.

Acerca da Ecologia particular à nossa espécie, o mesmo Lefèvre-Witier sustenta que ela é antes de tudo "uma forma de pensamento onde se impõe em permanência o relativismo, a comparação, a probabilidade, o todo para compreender um objecto", a qual, partindo de diferentes abordagens disciplinares, inicia um passo metodológico, tendo em conta as dinâmicas das interacções bioculturais nos ecossistemas. E logo a seguir precisa que essa integração "permite uma atitude científica de abertura a campos de conhecimento através do estudo do equilíbrio dinâmico nos ecossistemas onde o homem está ele próprio implicado ou é neles implicado".

A abertura que a Ecologia possibilita leva Deléage (1993: 254) a afirmar que ela incita-nos "a sair de oposições estéreis entre reducionismo e holismo, análise e síntese, conflito e cooperação". Já Acot (1988: 244-245) sustenta que para lá das "sensibilida- 
des singulares, das escolas de pensamento e dos comprometimentos políticos, a história da ecologia e a do ecologismo convidam-nos a reflectir sobre a hipótese da existência de um vínculo entre a emergência de novas relações entre os homens e a natureza e de novas relações entre os homens consigo próprios".

\section{Conclusão}

Durante tempo o Homem esteve arredado do objecto de estudo da Ecologia, apesar dos efeitos acumulados das suas intervenções nos ambientes de relação.

O reconhecimento e a afirmação da Ecologia Humana foram condicionados pelos paradigmas do determinismo ambiental e do possibilismo antropocênctrico. Praticamente só a partir dos anos 70 do séc. $X X$ é que os pontos de vista dos cientistas naturais e sociais começaram a fundir-se num consenso quanto ao papel da Ecologia Humana no diálogo Homem-Homem e Homem-Natureza. A Ecologia deixou de implicar apenas as Ciências Naturais, passando a interessar as Ciências Sociais, daí emergindo a Ecologia Humana.

Trata-se de uma Ecologia aplicada a uma espécie específica - o Homem, mas encarado como um factor ecológico novo sobre o planeta-Terra, simultaneamente autor e actor (Lamy, 2001).

A sua vocação interdisciplinar/transdisciplinaridade e o exercício profissional possibilitam a geração de conhecimento para a resolução de problemas. Esta nova e diferente dimensão de análise propicia pensar global-agir local em permante interacção.

Sem poder ignorar-se que grandes decisões tomadas a nível global são susceptíveis de alterar os diferentes ambientes, tal como a consequente responsabilidade primária cometida aos poderes constituídos, certo é que a compreensão das mudanças à escala planetária tem a sua origem em múltiplas atitudes e decisões do nosso quotidiano. Por exemplo, decisões como reduzir o abate de árvores, adquirir uma viatura de grande ou de pequena cilindrada, de recolher separadamente 0 lixo, utilizar ou não produtos reciclados, mas também e designamente, construir edifícios sem obstáculos ao regular acesso, circulação e utilização relativamente a todos os indivíduos, incluindo os que, de forma temporária ou não, tenham condicionamentos específicos ao nível da locomoção, promover o acesso à informação e a comunicação em suportes adequados, tais como em braille (enquanto meio natural de leitura e escrita das pessoas cegas), ou através do apoio de intérpretes de língua gestual, de molde a contemplar, também, respectivamente, quem não vê e quem não ouve, bem como tantas outras opções no quotidiano, não terão subjacentes atitudes que, uma vez interiorizadas, "banalizadas", multiplicadas, influem nas condições ecológicas do Planeta? (Carvalho, 2007).

Em jeito de remate e acompanhando Lamy (2001), assim possa a Ecologia Humana contribuir, da ciência à ética, para uma consciencialização colectiva.

\section{Notas}

1921 é também apontado na literatura como ano do aparecimento do termo Ecologia Humana, num trabalho de Park e Burguess sob o título An introduction of the science of sociology onde o termo é utilizado (Hawley, 1975: 21 e segs.).

2 Nesse sentido, Bews, citado por Hawley, embora reportando à Ecologia geral, salienta: "O meio, a função e o indivíduo constituem juntos o que pode ser chamado a tríade biológica fundamental. Essa tríade tem que ser estudada como um todo completo, e este estudo é o que se quer dizer essencialmente com a palavra ecologia" (1975: 23).

3 Era tal a polémica que Stouffer, escrevendo em 1940 sobre "oportunidades de intervenção", responde a Alihan deste modo: "Livre-se dessa coisa não sociológica - 'o espaço' e substitua-a por uma coisa sociológica, isto é substitua-a por 'oportunidades de intervenção"' (Young, 1983: 94-95). Daí à prevalência de que o "que não é sociológico, então está errado” era um passo.

\section{Referências bibliográficas}

ACOT, P. (1988), Histoire de l'Écologie, Paris, PUF.

ADAMS, C. (1983), "The relation of general ecology to human ecology", in G. Young (ed.), Origins of human ecology, Stroudsburg, $\mathrm{Pa}$, Hutchinson Ross, pp. 84-91.

ALIHAN, M. (1983), "Conspectus of the ecological approach", in G. Young (ed.), Origins of human ecology, Stroudsburg, $\mathrm{Pa}$, Hutchinson Ross, pp. 103-113.

ASCHER, F. (2000), "L'urbanisme face à la nouvelle révolution urbaine", in Qu'est-ce que la societé? vol. 3 (Université de tous les savoirs/dir. Yves Michaud), Paris, Odile Jacob, pp. 169-180.

AVELAR, T. e M. Pité (1996), Ecologia das populações e das comunidades: uma abordagem evolutiva do estudo da biodiversidade, Lisboa, Fundação Calouste Gulbenkian.

BARROWS, H. (1983), "Geography as human ecology", in G. Young (ed.), Origins of human ecology, Stroudsburg, Pa, Hutchinson Ross, pp. 49-62.

BORDEN, R. (1991), "Human ecology in the United States", in Human ecology, coming of age: an international overview, Yokohama, Japan, August 23-30 1990, Brussels, VUB, pp. 201-223.

BRANDÃO, M. (2003), "Considerações sobre o ramo ecológico da sociologia", Forum Sociológico, 9/10 (2. a série), Lisboa, Instituto de Estudos e Divulgação Sociológica da Faculdade de Ciências Sociais e Humanas da Universidade Nova de Lisboa, pp. 255-269. 
BUTTEL, F. (1988), "Sociologie et environnement: la lente maturation de l'écologie humaine", Revue Internationale des Sciences Sociales, 38, 109, Paris, UNESCO, pp. 359-379.

CAMPBELL, B. (1988), Ecologia humana, Lisboa, Edições 70 .

CARDEIRA, J. (1996), "Da ecologia humana à sociologia do ambiente", Mediterrâneo, 8 (Jan.-Dez. 1996), Lisboa, Instituto Mediterrânico, pp. 249-270.

CARVALHO, F. (2007), Educação de crianças com deficiência na perspectiva da ecologia humana, Lisboa, Secretariado Nacional para a Reabilitação e Integração das Pessoas com Deficiência.

CATTON, Jr., W. e R. Dunlap (1983), “Environmental sociology: a new paradigm", in G. Young (ed.), Origins of human ecology, Stroudsburg, $\mathrm{Pa}$, Hutchinson Ross, pp. 322-330.

CHABAUD, F. (1984), Écologie humaine ou la fin des diatomées, Paris, Privat, 1984.

COULON, A. (1997), L'École de Chicago, Paris, PUF.

CROGNIER, É. (1994), L'Écologie humaine, Paris, PUF.

DELÉAGE, J.-P. (1993), História da ecologia: uma ciência do homem e da natureza, Lisboa, Dom Quixote.

DI CASTRI, F. (1984), "Prefácio", in F. Chabaud, Écologie humaine ou la fin des diatomées, Paris, Privat.

EHRLICH, P. (1971), La bombe «P», Paris, J'ai lu.

HAWLEY, A. (1975), Ecología humana, Madrid, Tecnos.

HAWLEY, A. (1983), "Human ecology", in G. Young (ed.), Origins of human ecology, Stroudsburg, Pa, Hutchinson Ross, pp. 206-215.

HENS, J. [et al.] (1991), "European center for human ecology", in S. Suzuki (ed.), Proceedings of the symposium organized at the ocasion of the $V$ International Congress of Ecology (INTECOL), Yokohama, Japan, August 23-30 1990, Brussels, VUB, pp. 95-03.

JACOB, J. (1999), Histoire de l'écologie politique: comment la gauche a redécouvert la nature, Paris, Albin Michel.

JACQUARD, A. (2004), Lições de ecologia humana: da angústia à esperança, Lisboa, Instituto Piaget.

LAMY, M. (1995), As camadas ecológicas do homem, Lisboa, Instituto Piaget.

LAMY, M. (2001), L'introduction à I'écologie humaine, Paris, Elipses.
LESSA, A. (1984), "Prefácio", in P. Machado, Ecologia humana, São Paulo, Cortez, Conselho Nacional de Desenvolvimento Científico e Tecnológico, pp. 7-6.

MACHADO, P. (1984), Ecologia humana, São Paulo, Cortez, Conselho Nacional de Desenvolvimento Científico e Tecnológico.

MORIN, E. (1999), O método: a vida da vida, Mem Martins, Europa-América.

NAZARETH, M. (1993), "Demografia e ecologia humana”, Análise Social, 123/124, Lisboa, ICS, pp. 879-885.

NAZARETH, M. (1996), "Aspectos demográficos e de ecologia humana" in Bioética, Lisboa, Verbo, pp. 146-150.

NAZARETH, M. (1996 a) Introdução à demografia, Lisboa, Presença.

NAZARETH, M. (2004), Demografia: a ciência da população, Lisboa, Presença.

ODUM, E. (2001), Fundamentos de ecologia, Lisboa, Fundação Calouste Gulbenkian.

OLIVIER, G. (1981), La ecologia humana, Barcelona, Oikos-Tau.

ROSNAY, J. (1995), O macroscópio para uma visão global, Lisboa, Estratégias Criativas.

SAUVY, A. (1974), Crescimento zero?, Lisboa, Europa-América.

STEWARD, J. (1983), The concept and method of cultural ecology, in G. Young (ed.), Origins of human ecology, Stroudsburg, PA, Hutchinson Ross, pp. 63-76.

TAMAMES, R. (1983), Crítica dos limites do crescimento: ecologia e desenvolvimento, Mem Martins, Europa-América.

UNESCO (1986), "L'impact de l'environnement: sociologie, science politiques, sciences économiques, géographie, droit", Revue Internationale des Sciences Sociales, Vol. 38, 109, Paris, UNESCO.

VAYDA, A. e R. Rappaport (1983), "Ecology, cultural and noncultural", in G. Young (ed.), Origins of human ecology, Stroudsburg, PA, Hutchinson Ross, pp. 124-150.

YOUNG, G. (1983), "Human ecology: as an interdisciplinary concept: a critical inquiry", in Origins of human ecology, Stroudsburg, PA, Hutchinson Ross, pp. 355-399.

YOUNG, G. (ed.) (1983), Origins of human ecology, Stroudsburg, PA, Hutchinson Ross. 